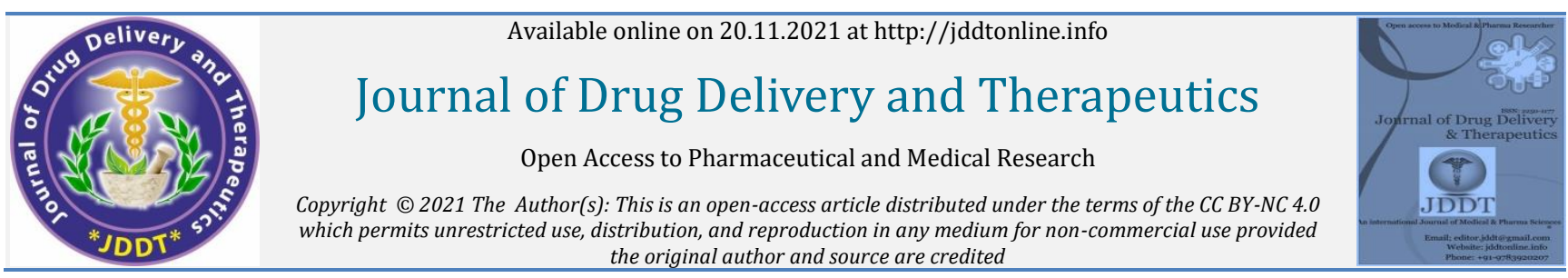
the original author and source are credited

Research Article

\title{
Development and Evaluation of Gastro Retentive Floating Drug Delivery System of Ondansetron Hydrochloride
}

\author{
Abadhesh Kumar Niranjan* (D), Aditya Kumar \\ Department of Pharmaceutics, Hygia Institute of Pharmaceutical Education and Research, Ghaila road, Gazipur Balram, Lucknow-226020, Uttar \\ Pradesh, India
}

Article Info:

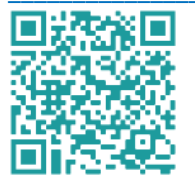

\section{Article History:}

Received 09 September 2021 Reviewed 29 October 2021 Accepted 13 November 2021 Published 20 November 2021

Cite this article as:

Niranjan AK, Kumar A, Development and Evaluation of Gastro Retentive Floating Drug Delivery System of Ondansetron Hydrochloride, Journal of Drug Delivery and Therapeutics. 2021; 11(6):150-158

DOI: http://dx.doi.org/10.22270/jddt.v11i6.5084

\section{*Address for Correspondence:}

Abadhesh Kumar Niranjan, Associate Professor, Department of Pharmaceutics, Hygia Institute of Pharmaceutical Education and Research, Ghaila road, Gazipur Balram, Lucknow- 226020, Uttar Pradesh, India

ORCID ID: https://orcid.org/0000-0002-2407-6902

\section{Abstract}

The Aim of the present study was to develop \& evaluate Gastro-retentive floating Tablet of Ondansetron hydrochloride. The Objective was to calibrate and validate the UVspectroscopy analytical method and to prepare and optimize the GR Floating tablets of Ondansetron hydrochloride in terms of dissolution release profile. The FDDS of the drug can minimize the fluctuation of drug plasma levels and result to associated adverse reactions, dosing frequency, and improved patient compliance. Conventionally, Ondansetron hydrochloride is taken up 2-3 times daily in the treatment of nausea and vomiting. Gastro retentive floating tablet of Ondansetron hydrochloride is better suited for treatment of postoperative nausea vomiting. In the present study, nine Gastro retentive Floating tablet formulations (F1, F2.....F9) of Ondansetron hydrochloride were prepared by the method of direct compression and polymers HPMC K15 were used and Guargum and Chitosan, in different quantity to normalise their effect on the' release profile of drug . Target release profile was $>80 \%$ release of drug in 12 hours. Tablets were evaluated for various parameters namely: thickness, weight variation', friability, hardness, assay, in-vitro buoyancy study \& drug release. Formulation F8 containing Chitosan $(26.66 \% \mathrm{w} / \mathrm{w})$, Guargum $(26.66 \% \mathrm{w} / \mathrm{w})$ and Sod. Carbonate $(25.83 \% \mathrm{w} / \mathrm{w})$ had the desirable release profile.

Keywords: Ondansetron hydrochloride; Gastro retentive floating tablet, Chitosan, Guar gum, Drug release

\section{INTRODUCTION}

Drug taken by oral administration is that the foremost easy and favourite suggests that of any other drug delivery to the systematic circulation of the body. Nowadays Oral drug delivery system have been accelerated interest in pharmaceutical industries field to gain enhanced therapeutic benefits of drug, like simple dose drug 'administration, patient conformity and flexibility' in formulation of drug. Medicine which can be simply absorbed by alimentary canal or gastro intestinal tract (GIT) and have short half-life therefore it is eliminated very fast from the body cavity. Regular dosage of medicine is necessary to gain appropriate therapeutic effect 1 .

To stay away from these type of restriction, the appropriate result of Oral Sustained-Controlled release Formulations have a good chance to release the drug gradually into the alimentary canal and in the Gastro- intestinal tract 2 (GIT) and It maintain an efficient amount of concentration level of drug in the circulation for lengthy time period. Once a drug taken by oral (administrative drug) route, such type of drug delivery path would be prevented release of drug in the abdomen and the drug release during a very guarded manner, so that the drug are often equipped instantly on the absorption site among the GIT channel ${ }^{3}$.

These path of Drug Delivery Systems (DDS) mainly face two type of adverse condition; firstly it shows very less gastric retention time (GRT) and also shows Unpredictable minimum GET, which may end in partial drug unleash from the measure type between the absorptive zone (Stomach or higher area of small intestine') resulting in diminish effectualness of administered drug dose. To specific site of drug which is taken by the path of 'orally administered controlled release' measure form DDS, It is fascinating to know a prolong retention period by the path of drug delivery. long-lasting gastric retentive drug improves the drug bioavailability., will increase the amount of drug dosage unleash, decreases drug wastage, and enhance solubility of the drug that square measure became less soluble throughout a high level proton concentration setting 4 . Conjointly prolonged GRT among the abdomen are often helpful in the confined action among the uppermost region of the GIT (Ex. Ulcer treatment), (Amit Kumar Nayak 2010). 
Gastro-retentive DDS is associated to prolong approach of stomachal period, by use of targeting site-specific drug which is released among GIT upper channel for local or general effects ${ }^{5}$. Gastro mindful measure forms will stay among the stomachal part for long time periods and thus considerably increase the stomachal withholding time gastric retention time (GRT) of medication. the previous few years many gastro retentive drug delivery system(DDS) approaches being designed and developed, including high density (sinking) systems which means preserved within rock bottom of the abdomen, rarity (floatation) systems which is reason of buoyancy in stomachal fluid, Muco-adhesive systems which increase bioadhesion of drug in to abdomen , membrane extendible swellable, unfoldable, or systems that have a limits removal of the measure forms by the help of the sphincter of abdomen magnetic systems, super porous gel systems ${ }^{6}$, etc.

\section{Requirement of Gastro-retention}

○ The drugs which are absorbed in the variable gastric emptying time.

- Those drugs which are absorbed by the help of GIT's proximal part.

- General or Sustained drug delivery (SDD) intended to the stomach and proximal part of the small intestine to treat many types of diseases 7 .

- Drugs which are insoluble and not degrade at the basic pH levels.

- Certain type of 'peptic ulcers caused by H. Pylori. (Amit Kumar Nayak et al., 2010').

\section{Aspects of GRDDS Formulation:}

- The drug should not contain any effect on gastric motility of GIT 8 .

- It should be suitable to ingest for patients.

○ The formulation must show complete 'degradation and evacuation of the system when the drug completely releases.

○ It shows very effective retention in the stomach ${ }^{9}$.

- The drug must contain proper amount of drug dose loading capacity \& also control drug release report.

- It should not give any side effects or other common unwanted action.(Vinod K.R. et al., 2010)

\section{MATERIALS AND METHODS}

Ondansetron was obtained as a gift from Aurobindo Pharma Ltd. Gaddapotharam, Andhra Pradesh. HPMC K 15 M, Chitosan \& Guar gum were procured from Sigma Aldrich. All other substances were of analytical grade. All chemicals were pure and of analytical grade.

\section{Drug Identification}

\section{Organoleptic property of the drug}

The drug evaluated for the organoleptic property like color, odor.

\section{Melting point observation}

Melting point of ONDCL is found to be $182^{\circ} \mathrm{C}$.

\section{Analytical Methodology}

\section{Determination of $\lambda_{\max }$ of ONDCL}

$0.1 \mathrm{mg} / \mathrm{ml}$ concentration of ONDCL stock solution was prepared in distilled water and further $(0.5 \mathrm{ml}$ in $10 \mathrm{ml})$ diluted with water to obtain $5 \mu \mathrm{g} / \mathrm{ml}$ concentration solution. This prepared solution of compound was scanned in UVVisible spectrophotometer in the range of 200-400nm using distilled water as blank at the wavelength of $310 \mathrm{~nm} \lambda_{\max }$ of ONDCL was recorded.

\section{Standard Calibration Curve}

\section{Preparation of standard stock solution}

ONDCL $10 \mathrm{mg}$ was weighed in $100 \mathrm{ml}$ volumetric flask and the solution prepare to the mark in volumetric flask with distilled water to acquire $0.1 \mathrm{mg} / \mathrm{ml}$ solution.

\section{Preparation of calibration and samples validation}

Calibration sample $(5,10,15,20,25 \mu \mathrm{g} / \mathrm{ml})$ in the singlet and validation samples $(6,16,24 \mu \mathrm{g} / \mathrm{ml})$ in triplicate were prepared by appropriate dilution of stock solution.

\section{Preparation of calibration curve}

The absorbance reading of calibration and validation samples were measured against distilled water as blank in UV-Vis. spectrophotometer at $310 \mathrm{~nm}\left(\lambda_{\max }\right)$. Then absorbance values of the calibration sample were plotted against their respective concentration to obtain the calibration curve.

\section{Validation of the analytical method}

\section{Linearity}

The absorbance value of the calibration sample was plotted against their respective concentration to obtain the calibration curve, and linear regression was performed 10 . Linearity was accessed by correlation coefficient determination $\left(\mathrm{r}^{2}\right)$.

\section{Accuracy}

Mean concentration value for each data of validation samples were calculated and \%error (a measure of accuracy) for each concentration calculation with the formula,

$$
\begin{gathered}
\text { \%error }=\text { (calculated mean concentration-actual } \\
\text { concentration }) / \text { actual concentration*100. }
\end{gathered}
$$

\section{Precision}

Percentage relative standard deviation value was calculated (as a measure of precision) for each set of concentration by given formula,

\section{$\%$ RSD = standard deviation $/$ calculated mean concentration*100.}

\section{Drug excipients interaction study by FT-IR}

The interaction studies of various excipients with ONDCL 11 recorded by FT-IR Analysis. 
Table 1: The ratio of ONDCL and excipients blend. (Yadav Priyanka. 2014)

\begin{tabular}{|l|l|l|l|}
\hline Sr. No. & Excipients & Ratio w/w & Total blend mg \\
\hline 1 & Pure Drug & $1: 1$ & 100 \\
\hline 2 & Drug + HPMC K15 & $1: 1$ & 100 \\
\hline 3 & Drug + Guargum & $1: 1$ & 100 \\
\hline 4 & Drug + Sod. Bicarbonate & $1: 1$ & 100 \\
\hline 5 & Drug + Chitosan & $1: 1$ & 100 \\
\hline
\end{tabular}

\section{Preparation of blend for Formulation}

Table 2: Ingredients used in tablets formulations;

\begin{tabular}{|l|l|l|l|l|l|l|l|l|l|l|}
\hline Sr.no & Ingredients & F1 & F2 & F3 & F4 & F5 & F6 & F7 & F8 & F9 \\
\hline $\mathbf{1}$ & Ondansetron & 32 & 32 & 32 & 32 & 32 & 32 & 32 & 32 & 32 \\
\hline $\mathbf{2}$ & Sod. Carbonate & 42.5 & 47.5 & 52.5 & 57.5 & 62.5 & 67.5 & 72.5 & 77.5 & 82.5 \\
\hline $\mathbf{3}$ & HPMC K 15 M & 80 & 40 & 40 & 160 & ---- & $-\cdots--$ & 80 & $-\cdots--$ & 80 \\
\hline $\mathbf{4}$ & Guar gum & 40 & 80 & 40 & $-\cdots--$ & 160 & $-\cdots--$ & 80 & 80 & $-\cdots-$ \\
\hline $\mathbf{5}$ & Chitosan & 40 & 40 & 80 & $-\cdots--$ & $-\cdots--$ & 160 & ---- & 80 & 80 \\
\hline $\mathbf{6}$ & Mg stearate & 2.5 & 2.5 & 2.5 & 2.5 & 2.5 & 2.5 & 2.5 & 2.5 & 2.5 \\
\hline $\mathbf{7}$ & Purified Talc & 3 & 3 & 3 & 3 & 3 & 3 & 3 & 3 & 3 \\
\hline $\mathbf{8}$ & Lactose & 60 & 55 & 50 & 45 & 40 & 35 & 30 & 25 & 20 \\
\hline & Total Quantity & 300 & 300 & 300 & 300 & 300 & 300 & 300 & 300 & 300 \\
\hline
\end{tabular}

\section{Evaluations of Powder Blend for Tableting}

Pre-compressional evaluation of powder blend:

For pre-compressional study of the powder blend of all the formulations was examine by the as angle of repose, tapped density, Hausner's ratio and bulk density ${ }^{12}$.

\section{Angle of repose ( $\theta$ )}

The formulated powder blend is intended to measurement of $\boldsymbol{\theta}$ and this is found in the range of $27^{\circ} .08^{\prime}-30^{\circ} .26^{\prime}$, which shows a good flow property of formulated powder blend'. Results were given in Table no. 8.

Bulk density: For the measurement of Bulk density of the material (powder blend) in the range between $0.299 \mathrm{~g} / \mathrm{ml}$ $0.307 \mathrm{~g} / \mathrm{ml}$, which shows that the formulated powder blends were not too bulky ${ }^{13}$. That result was shown in Table no. 8.

Tapped density: Tapped density of the powder blend was within the range between $0.422 \mathrm{~g} / \mathrm{ml}-0.45 \mathrm{~g} / \mathrm{ml}$. The results were shown in Table no. 8.

Hausner's Ratio: For the measurement of the Hausner's ratio of the compound material was found to be within 1.36 to 1.43 , which shows that flow properties are good for formulated powder blend ${ }^{14}$. The results were shown in Table no. 8.

In the above results -It had been concluded that the angle of repose $\left(<30^{\circ}\right)$ indicate good flow properties of the formulated powder blend. It was additionally followed by very good flow properties. Density and hardness of powder were interconnected properties. And also powder density may be tablet porosity, influence compressibility, dissolution, and other properties. Results indicate that the powder blend of all the formulations possessed adequate flow properties (Amit K. Jain et al., 2011).

\section{Formulation of ONDCL Gastroretentive Floating Tablets}

\section{Method of Preparation}

All the materials were weighed and sieved by $300 \mu \mathrm{m}$ (\#50) sieve and mix with a mortar and pestle. The powder blend was directly compressed into core tablet using $9 \mathrm{~mm}$ circular biconcave punch on Rotatory tablet punching machine 15 . Tablets were like $32 \mathrm{mg}$ of ONDCL (tablet weight $300 \mathrm{mg}$ ).

\section{Evaluation of Floating Tablets of ONDCL}

\section{Post-compressional estimation of Ondansetron hydrochloride floating tablet:}

Formulated Tablets which were subjected to assessment tests these also shows general appearance, friability, hardness, diameter, thickness, weight variation and drug content 16

\section{General appearance:}

Prepared tablets were white and some batches show some variation in colour, round, biconvex shaped without any defect on sides. Every tablet was pleasurable to the eye in appearance ${ }^{17}$.

\section{Hardness of tablet:}

Hardness is the basic parameter of tablets were measured by the instrument Monsanto hardness tester and was found between of 3.5 - 4 kilogram per square centimeter, which shows that good mechanical strength and provide great ability to withstand chemical and physical stress though handling during transportation and loadingunloading ${ }^{18}$. The results were shown in Table 9.

\section{Diameter and Thickness of tablets:}

The diameter and thickness of all the formulations were 
measured by instrument Vernier scale micrometer 19 and were ranged between $3.5-4 \mathrm{~mm}$, this indicate the uniformity of tablets with having the similar particle size distribution in the formulation and no deformity. The results were mentioned in Table no. 9.

Friability Test of the tablets: Friability of all the formulation was lie between $0.1 \%-0.80 \%$ and the friability was less than $1 \%$ altogether the formulations, which shows that a good mechanical resistance of the tablet. The values of Hardness test and friability Percentage indicates good handling property of finally prepared tablets ${ }^{20}$. Results were shown in Table no. 9.

\section{Weight variation Test of the all formulation:}

For the analysis of weight variation it should performed according to the procedure given in the pharmacopoeia. All the developed tablet formulations (Fl to F9) passes weight variation test because the percentage weight variation range within the pharmacopoeial standard limit $( \pm 5 \%)$. hence all the formulations of tablet are acceptable. The results are given in Table no. 9.

\section{Evaluation/ Estimation of tablet ingredient:}

In the formulation for estimation of percentage of all the ingredient was in the range $99 \%$ to $104 \%$ and this confirm 'that the drug was uniformly distributed in' the all tablets.
Here the share of drug content in the entire formulations tablets are compressed with official specification: as per U.S.P (Ranges: $90 \%$ to $110 \%$ ) 21 . The results/data were shown in Table no. 9.

From the above result it had been concluded that each one the tablet formulation shows standard pharmacopoeial specification \& formulated with the pharmacopoeial standard for friability, drug content, and weight variation. (Jain A K. or USP 30, NF2007)

\section{In Vitro Buoyancy Studies:}

The formulations takes time to emerge on the superior medium known as FLT (Floating Lag Time) sometime BLT (Buoyancy Lag Time) and the complete duration of time taken by individual tablet is named as TFT 22, 23 (Total Floating Time) (Margret Chandria et al., 2009; Riteshkumar et al., 2010; Ravikumar et al., 2009). In this regard the buoyancy studies results are often accomplished that the batch have HPMC only polymers and its combined with Sodium carbonate gives more relevant floating lag time in comparison to batch containing Guar gum polymers alone and its combination with HPMC. Floating of the tablet formulation shows variation from polymer to polymer that is governed by both the buoyancy of the hydrocolloid leading matter and the dissolution media. (Nagarwal et al, 2010).

The conditions of dissolution test were as follows (IP. 2018)

Table 3: Dissolution test Conditions;

\begin{tabular}{|l|l|}
\hline Apparatus & Type-I Indian pharmacopeia (Paddle type) \\
\hline Analytical method & UV-spectroscopy $(310 \mathrm{~nm})$ \\
\hline Dissolution media & $500 \mathrm{ml}$ distilled water \\
\hline Speed and time & $50 \mathrm{rpm}$ for 15 hours \\
\hline Temperature & $37 \pm 0.5^{\circ} \mathrm{C}$ \\
\hline Sample amount & $5 \mathrm{ml}$ with replacement \\
\hline Sampling time & $30 \mathrm{~min}, 1 \mathrm{~h}, 2 \mathrm{~h}, 3 \mathrm{~h}, 4 \mathrm{~h}, 5 \mathrm{~h}, 6 \mathrm{~h}, 7 \mathrm{~h}, 8 \mathrm{~h}, 9 \mathrm{~h}, 10 \mathrm{~h}, 11 \mathrm{~h}, 12 \mathrm{~h}, 13 \mathrm{~h}, 14 \mathrm{~h}, 15 \mathrm{~h}$. \\
\hline
\end{tabular}

\section{RESULTS AND DISCUSSION}

\section{Analytical Method Development}

\section{Calibration of pure drug}

The pure drug absorbances with their respective concentrations are mentioned in below table.

Table 4: Pure drug absorbance with their respective concentrations

\begin{tabular}{|l|l|}
\hline Concentration $(\boldsymbol{\mu g} / \mathbf{m l})$ & Absorbance(nm) \\
\hline 5 & 0.154 \\
\hline 10 & 0.300 \\
\hline 15 & 0.458 \\
\hline 20 & 0.605 \\
\hline 25 & 0.741 \\
\hline
\end{tabular}

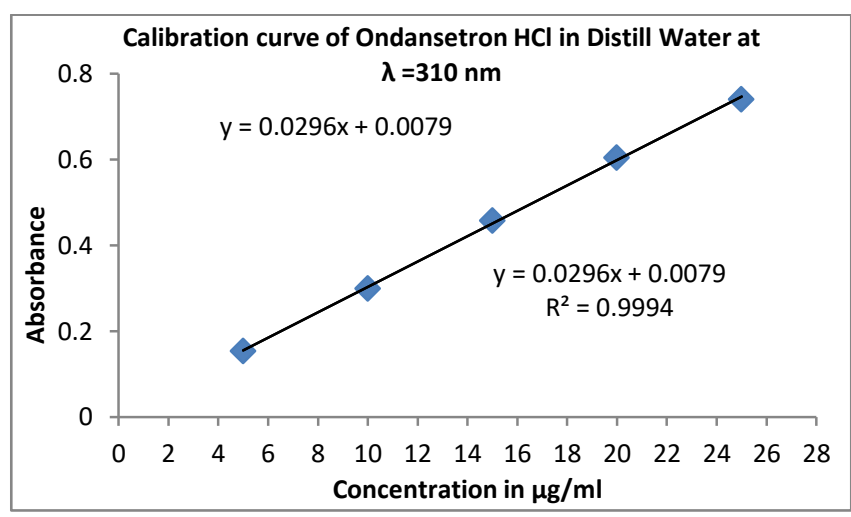

Figure 1: Calibration curve of pure drug and excipients by UV- spectroscopy

\section{Calibration data of drug with excipients}

The calibration data of drug with excipients is shown in below table. 
Table 5: Concentration and absorbance value of the calibration sample

\begin{tabular}{|l|l|}
\hline Concentration $(\boldsymbol{\mu g} / \mathbf{m l})$ & Absorbance(nm) \\
\hline 5 & 0.141 \\
\hline 10 & 0.287 \\
\hline 15 & 0.426 \\
\hline 20 & 0.574 \\
\hline 25 & 0.715 \\
\hline
\end{tabular}

\section{Validation of UV analytical method}

Linearity and range: Worth of correlation coefficient was found to be $\mathrm{r}^{2}=0.999$ in Conc. Taken from 5, 10, 15, 20, $25(\mu \mathrm{g} / \mathrm{ml})$, that indicated a linear graph in between concentration and absorbance. The spectrum for this method was $5-25(\mu \mathrm{g} / \mathrm{ml})$.

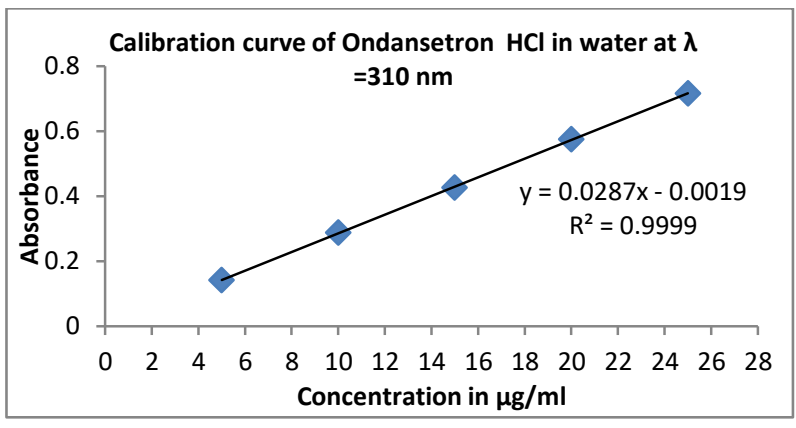

Figure 2: Calibration curve of pure drug and excipients by UV- spectroscopy

Accuracy and precision: The exactness (measured by \% error) and precision (measured by \% RSD) for both intraday and interday studies, as mentioned below, were found within the acceptable range of $2 \%$. Thus method was accurate as well as precise. The SD, RSD, accuracy, and precision data of intraday are recorded in table given below.

Table 6: Intraday accuracy and precision by UV spectroscopy method

\begin{tabular}{|l|l|c|c|c|l|}
\hline Actual conc. $(\boldsymbol{\mu g} / \mathbf{m l})$ & $\begin{array}{l}\text { Mean conc. } \\
(\boldsymbol{\mu g} / \mathbf{m l}) .\end{array}$ & SD & \% RSD & \% Bias & \% Drug recovery \\
\hline 6 & 6.24 & 0.020117 & 0.003221 & 4.08 & 104 \\
\hline 16 & 15.73 & 0.053224 & 0.003383 & -1.66 & 98.33 \\
\hline 24 & 24.03 & 0.034843 & 0.001449 & 0.15 & 100.15 \\
\hline
\end{tabular}

The RSD, accuracy, and precision data of intraday are recorded in table given below.

Table 7: Intraday accuracy and precision by UV spectroscopy method

\begin{tabular}{|c|l|l|l|l|l|l|}
\hline Actual Conc. $(\boldsymbol{\mu g} / \mathbf{m l})$ & Day 1 & Day 2 & Day 3 & Mean conc. & \% Error & \% RSD \\
\hline 6 & 5.88 & 6.24 & 6.06 & 6.06 & 1 & 2.9 \\
\hline 16 & 15.96 & 15.73 & 16.09 & 15.92 & -0.45 & 1.14 \\
\hline 24 & 23.29 & 24.03 & 24.00 & 23.77 & -0.94 & 1.76 \\
\hline
\end{tabular}

\section{Estimation Parameter of Powder Blend}

The estimation parameter like angle of repose, bulk density, tapped density, Hausner's ratio, given the following table given below.

Table 8: Evaluation parameters and values;

\begin{tabular}{|l|l|l|l|l|l|l|l|l|l|}
\hline Parameters & $\mathbf{F}_{\mathbf{1}}$ & $\mathbf{F}_{\mathbf{2}}$ & $\mathbf{F}_{\mathbf{3}}$ & $\mathbf{F}_{\mathbf{4}}$ & $\mathbf{F}_{\mathbf{5}}$ & $\mathbf{F}_{\mathbf{6}}$ & $\mathbf{F}_{\mathbf{7}}$ & $\mathbf{F}_{\mathbf{8}}$ & $\mathbf{F}_{\mathbf{9}}$ \\
\hline Bulk density & 0.299 & 0.30 & 0.30 & 0.306 & 0.30 & 0.30 & 0.30 & 0.306 & 0.307 \\
\hline Tapped density & 0.45 & 0.44 & 0.43 & 0.434 & 0.434 & 0.428 & 0.428 & 0.422 & 0.424 \\
\hline Hausner's ratio & 1.43 & 1.41 & 1.43 & 1.41 & 1.44 & 1.426 & 1.42 & 1.37 & 1.36 \\
\hline Angle of repose & $27^{\circ} .08^{\prime}$ & $27^{\circ} .36^{\prime}$ & $28^{\circ} .16^{\prime}$ & $27^{\circ} .76^{\prime}$ & $28^{\circ} .34^{\prime}$ & $28^{\circ} .55^{\prime}$ & $29^{\circ} .21^{\prime}$ & $30^{\circ} .11^{\prime}$ & $30^{\circ} .26^{\prime}$ \\
\hline
\end{tabular}




\section{FT-IR Analysis}

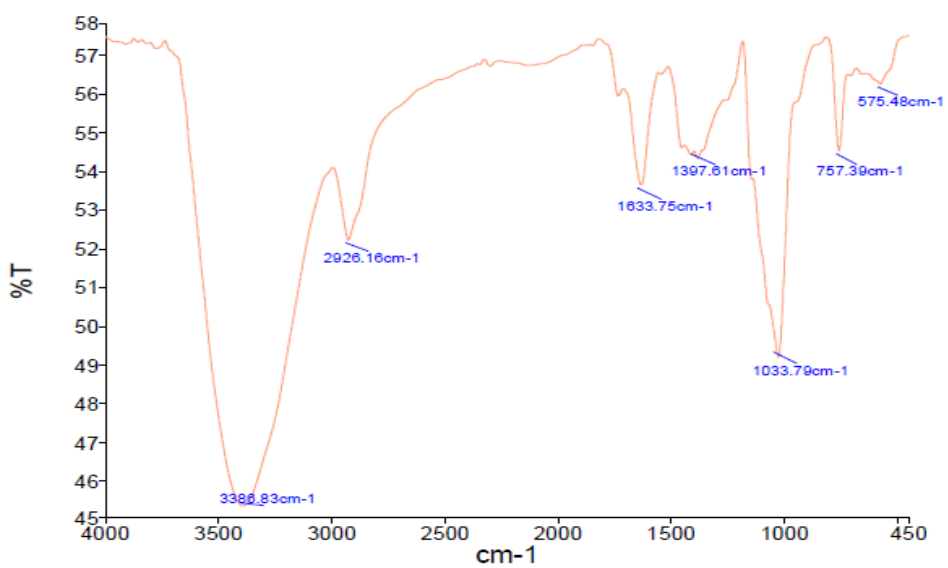

Figure 3: FTIR of ONDCL (Pure Drug)

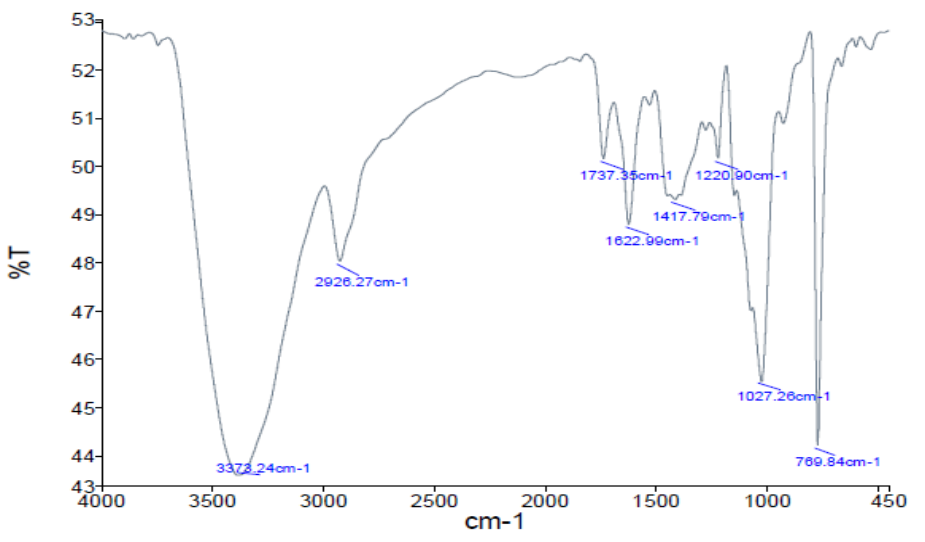

Figure 4: FTIR of ONDCL and HPMC K15M

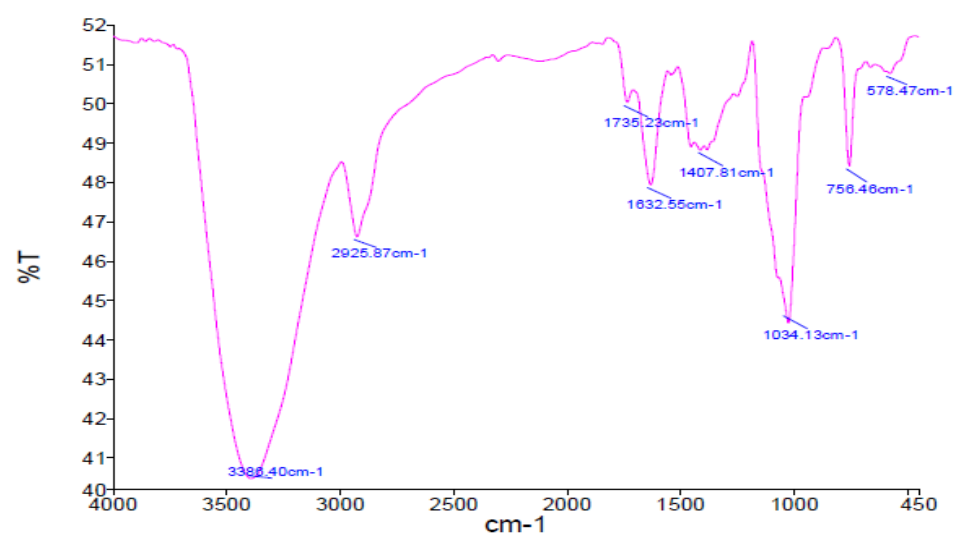

Figure 5: FTIR of ONDCL and Guargum

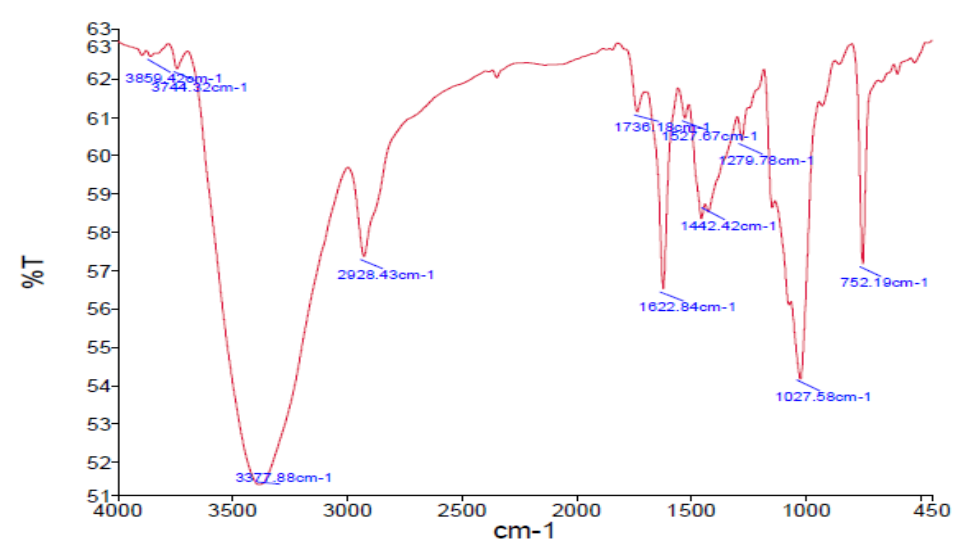

Figure 6: FTIR of ONDCL and Sodium Carbonate 


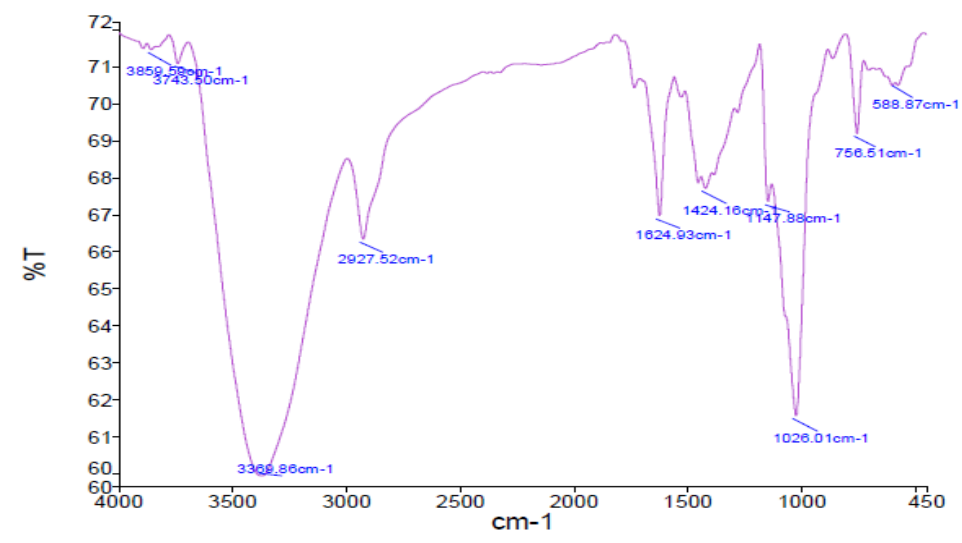

Figure 7: FTIR of ONDCL and Chitosan

\section{Evaluation of Formulated Tablets}

In the estimation parameters of the formulations like diameter, hardness, weight variation, thickness, friability, and percentage drug Ingredient were given in below table.

Table 9: Evaluation parameters and their values

\begin{tabular}{|l|l|l|l|l|l|l|l|l|l|}
\hline PARAMETERS & F-1 & F-2 & F-3 & F-4 & F-5 & F-6 & F-7 & F-8 & F-9 \\
\hline Weight variation & $99 \pm 1$ & $99 \pm 1$ & $99 \pm 1$ & $99 \pm 1$ & $99 \pm 1$ & $99 \pm 1$ & $99 \pm 1$ & $99 \pm 1$ & $99 \pm 1$ \\
\hline Thickness & 1.67 & 1.66 & 1.68 & 1.69 & 1.68 & 1.67 & 1.68 & 1.66 & 1.67 \\
\hline Diameter & 4.00 & 3.99 & 3.52 & 3.73 & 3.50 & 3.63 & 3.52 & 3.53 & 3.93 \\
\hline Hardness & $3 \pm 0.5$ & $3 \pm 0.5$ & $3 \pm 0.5$ & $3 \pm 0.5$ & $3 \pm 0.5$ & $3 \pm 0.5$ & $3 \pm 0.5$ & $3 \pm 0.5$ & $3 \pm 0.5$ \\
\hline Friability & $0.8 \%$ & $0.5 \%$ & $0.7 \%$ & $0.6 \%$ & $0.8 \%$ & $0.5 \%$ & $0.4 \%$ & $0.1 \%$ & $0.3 \%$ \\
\hline \% drug content & $102 \%$ & $104 \%$ & $100.2 \%$ & $101.1 \%$ & $99.2 \%$ & $99 \%$ & $99.9 \%$ & $99.2 \%$ & $98.5 \%$ \\
\hline
\end{tabular}

\section{Dissolution test}

The dissolution study of Gastro Retentive Floating tablets of ONDCL using USP type 2 dissolution apparatus which shown in table no. 10.

Table 10: All formulations percentage drug release with the respect of time

\begin{tabular}{|c|l|l|l|l|l|l|l|l|l|}
\hline \multicolumn{9}{|c|}{ \% Drug release } \\
\hline Time(h) & F-1 & F-2 & F-3 & F-4 & F-5 & F-6 & F-7 & F-8 & F-9 \\
\hline 0.5 & 62.159 & 49.165 & 46.131 & 42.404 & 29.120 & 29.056 & 26.556 & 22.47540 & 22.654 \\
\hline 1 & 78.476 & 70.493 & 64.118 & 70.807 & 47.275 & 45.813 & 41.49 & 32.55081 & 31.564 \\
\hline 2 & 91.482 & 94.601 & 80.233 & 96.073 & 68.121 & 64.341 & 46.58 & 43.14467 & 42.236 \\
\hline 3 & 94.063 & 108.64 & 83.331 & 105.60 & 74.004 & 73.953 & 63.78 & 50.31844 & 49.523 \\
\hline 4 & 95.312 & 114.09 & 84.745 & 108.30 & 85.377 & 76.324 & 66.78 & 54.95942 & 57.425 \\
\hline 5 & 97.573 & 117.68 & 86.409 & 110.23 & 86.817 & 79.292 & 72.91 & 57.71926 & 59.452 \\
\hline 6 & 98.062 & 120.00 & 87.271 & 112.59 & 87.872 & 79.921 & 73.45 & 60.57032 & 62.845 \\
\hline 7 & 105.74 & 125.76 & 90.326 & 118.48 & 93.074 & 81.743 & 66.71 & 61.72459 & 63.953 \\
\hline 8 & 109.04 & 127.71 & 93.310 & 128.12 & 96.268 & 86.616 & 78.15 & 62.925 \\
\hline 9 & 110.19 & 130.44 & 93.016 & 131.18 & 97.839 & 88.394 & 80.03 & 65.5647 & 67.968 \\
\hline 10 & 112.78 & 132.18 & 99.190 & 133.27 & 98.449 & 89.792 & 81.43 & 66.5781 & 69.435 \\
\hline 11 & 113.28 & 132.61 & 101.07 & 132.77 & 99.747 & 90.729 & 82.67 & 73.74959 & 72.624 \\
\hline 12 & 114.66 & 127.67 & 101.12 & 137.07 & 99.804 & 90.743 & 87.56 & 82.62827 & 79.652 \\
\hline 13 & 116.33 & 130.59 & 101.30 & 131.32 & 100.98 & 91.405 & 89.11 & 87.90040 & 88.785 \\
\hline 14 & 117.40 & 134.28 & 102.85 & 132.48 & 101.36 & 92.333 & 92.22 & 94.80778 & 93.245 \\
\hline 15 & 117.79 & 128.98 & 101.25 & 133.70 & 102.76 & 93.867 & 96.63 & 98.96598 & 96.865 \\
\hline
\end{tabular}




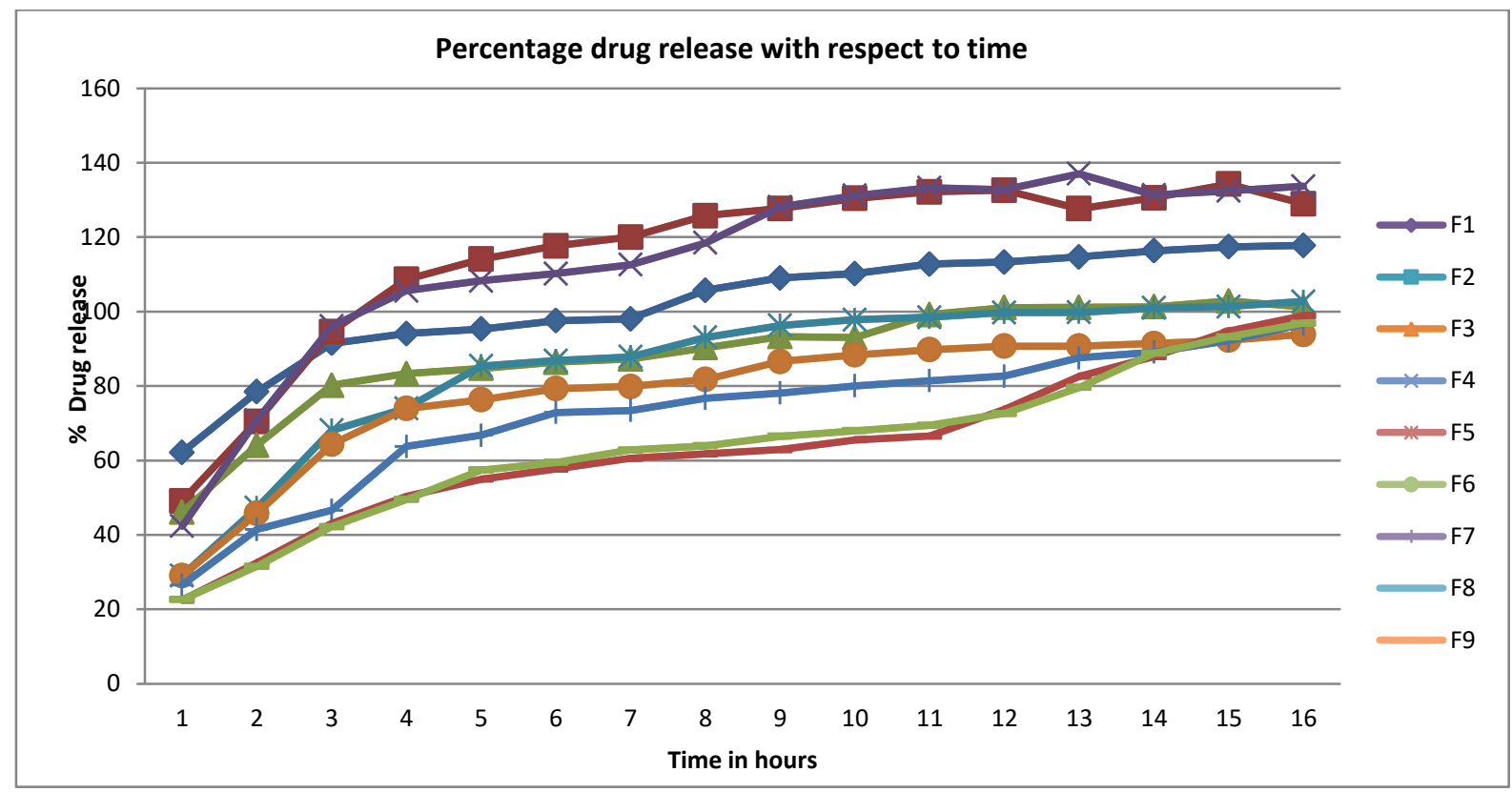

Figure 8: Release profile of ONDCL

The Gastro Retentive formulation $\left(\mathrm{F}_{8}\right)$ of ONDCL was given maximum release in the distilled water, so this formulation could be used for further study.

In Vitro Buoyancy Studies:

Table 11: Floating Study of ONDCL Tablets

\begin{tabular}{|l|l|l|}
\hline Formulation Code & Buoyancy Lag Time & Total Floating Time (Hrs) \\
\hline F1 & Floats Immediately & $>24 \mathrm{hrs}$ \\
\hline F2 & Floats Immediately & $>24 \mathrm{hrs}$ \\
\hline F3 & Floats Immediately & $>24 \mathrm{hrs}$ \\
\hline F4 & Floats Immediately & $>24 \mathrm{hrs}$ \\
\hline F5 & Floats Immediately & $>24 \mathrm{hrs}$ \\
\hline F6 & Floats Immediately & $>24 \mathrm{hrs}$ \\
\hline F7 & Floats Immediately & $>24 \mathrm{hrs}$ \\
\hline F8 & Floats Immediately & $>24 \mathrm{hrs}$ \\
\hline F9 & Floats Immediately & $>24 \mathrm{hrs}$ \\
\hline
\end{tabular}
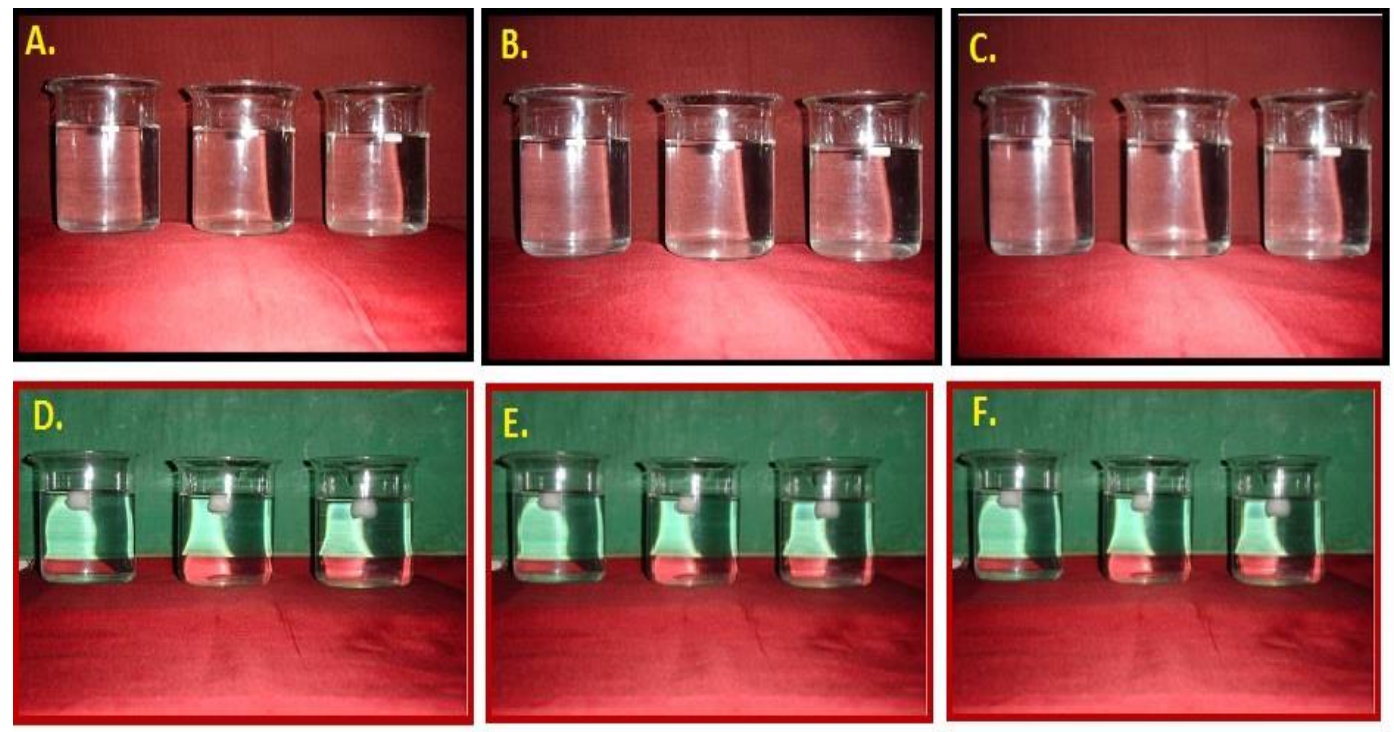

Figure 9: Floating Study (A. F1, F2 \& F3 Floats instantly, B. F4, F5 \& F6 Floats instantly,C. F7, F8, \& F9 Floats instantly, D. F1, F2 \& F3 Still Floats after 12 Hours E. F4, F5 \& F6 Still Floats After 12 Hours, F. F7, F8, \& F9 Still Floats After 12 Hours) 


\section{CONCLUSION}

In the present study result is visibly point out the probability to prepare Ondansetron hydrochloride in the form of FDDS with extension of GRT and controlled drug release. The upcoming studies may be extension to disclose the pharmacokinetic parameters which is associated to bioavailability and clinical studies of upcoming compounds, which may prove that this type of the formulation safely administered for the curing from nausea with improved therapeutic efficacy. Gastro retentive Floating tablet (F1, F2, F3, F4, F5, F6, F7 F8 \& F9) of the Ondansetron hydrochloride were directly compressed formulation which was prepared by using HPMC K15, Chitosan, Guargum and Sodium Bicarbonate. 'All the formulations were studied for hardness, weight variation, thickness, friability', assay, drug release and Floating studies. Formulation $\mathrm{F}_{8}$ had achieved the target release profile of $>80 \%$ in $12 \mathrm{~h}$. F-8 formulation stored for further product development studies.

\section{Acknowledgments}

The authors are grateful to Hygia Institute of Pharmaceutical Education \& Research, Lucknow, U.P. for providing research facilities.

\section{Conflict of Interest}

The authors declare that they have no conflicts of interest.

\section{REFERENCES}

1. Kulkarni A, Bhatia M, Development and evaluation of region selective bilayer floating tablets of atenolol and lovastatin for biphasic release profile. Ira. J. Pharm. Res., 2009; 8(1):15-25.

2. Agarwal G, Agarwal S, Karrar PK, Goel S, "Oral Sustained Release Tablets: An Overview with a Special emphasis on Matrix Tablet". American Journal of Advance Drug Delivery, 2017; 5 (02):27-32.

3. Bagherwal A, Patidar DK, Sharma P, Studies on formulation and evaluation of floating tablets of ciprofloxacin $\mathrm{HCl}$. Int. J. Compr. Pharm., 2010; 5(02):1-4.

4. ApuSarker A, Pthana, D.Shrestha, Golam K, and RezaulJalil."Investigation of In vitro Release Kinetics of Carbamazepine from Eudragits RSPO and RLPO Matrix tablets". Trop J Pharm, 2009; 8 (2):145 https://doi.org/10.4314/tjpr.v8i2.44523

5. Brahmankar D.M., Jaiswal S.B., "Biopharmaceutics and Pharmacokinetics A Treatise", Vallabh prakashan, New Delhi, 1995; 10th edition: $347-352$.

6. BD Priya, BV Lakshmi, V Bhavya, V Ramya, D Aparna, T Prasanti, and AL Rao. "Simultaneous determination of ranitidine hydrochloride in bulk and tablet dosage form by UV spectrophotometry". J pharm research, 2017; 1(5):1-6 https://doi.org/10.23880/OAJPR-16000128

7. Deshmukh T. B., Deo S.S., Inam F., Lambat T.L., Gurubaxani S. B., and Choudhari A.V. "Development and validation of Ondansetron hydrochloride in pharmaceutical dosage form by RP-HPLC method". IJASET, 2015; 1: 15-20.

8. Emami J, Tejeddin M, Ahmadi F. "Preparation and in-vitro evaluation of sustained release matrix tablets of Flutamide using synthetic and naturally occurring polymers". Int. J. Pharm. Res, 2008; 7(4):247-257.

9. Gilbert and Neil."Tablets".VARGHESE publishing house. 400014, $1990 ; 430-456$.

10. Gohel C., Patel P., and BariyaShital H. "Studies in Preparation and Evaluation of $\mathrm{pH}$ - Independent Sustained-Release Matrix Tablets of Verapamil HCl Using Directly Compressible Eudragits",
Pharmaceutical Development and Technology, 2003; 8(4):323-333 https://doi.org/10.1081/PDT-120024686

11. https://www.drugbank.ca/salts/DBSALT000921

12. https://scholar.google.com/

13. https://pubmed.ncbi.nlm.nih.gov/?term=grdds.

14. Indian Pharmacopoeia 2007, Govt. of India, Ministry of Health and Family Welfare. Delhi: Indian Pharmacopoeia Commission, Ghaziabad, "Tablets", 2007; 44:662-663.

15. Indian Pharmacopoeia 2018, Govt. of India, Ministry of Health and Family Welfare. Delhi: Indian Pharmacopoeia Commission, Ghaziabad,"Ondansetron Tablets" 2018; 3:2792-2793.

16. Indian Pharmacopoeia 2018, Govt. of India, Ministry of Health and Family Welfare. Delhi: Indian Pharmacopoeia Commission, Ghaziabad,"Ondansetron hydrochloride"2018; 3:2787.

17. Ibric Svetlana, jovanovic Milica, Djuric Zorica, Jelen Parojcic, solomun Ljiljana. "The Application of Generalize regression neural network in the modelling and optimization of aspirin extended release tablets with Eudragits RSPO as matrix substance". Journal of controlled release, 2002; 82:213-232

https://doi.org/10.1016/S0168-3659(02)00044-5

18. Jadhav S, Kharat R, Ansari A, Tamboli A."Estimation of Ondansetron hydrochloride in bulk and formulation by the secondorder derivative area under curve UV-spectrophotometric method". Pharma tutor, 2015; no.3 (8):42-46.

19. KD Tripathi, "Essential of medical pharmacology". Book, 2008; 6th edition https://doi.org/10.5005/jp/books/10282

20. Medikone S, Mukthinuthalapati MA, and Bukkapatnam V. "Novel analytical techniques for the determination of Ondansetron hydrochloride in pharmaceutical dosage forms by spectrophotometry". Jcps journal on analytical technique, 2015; no. 8 (4):863-866.

21. Mushabbarbasha MD, B Praveena, M. Srinidhi, SK. A. Rahanaman. "Method development and validation of Ondansetron in bulk and pharmaceutical dosage form by stability-indicating rp-HPLC method". Internation Journal of pharma tech research, 2013; (1)5:86-98.

22. Makhija N. Sapnna, and Vavia R. Pradeep. "Once daily sustained release tablets of venlafaxine, anovel antidepressant", European Journal of Pharmaceutics and Biopharmaceutics, 2002; 54:15 https://doi.org/10.1016/S0939-6411(02)00049-8

23. Nicholas, Leon, Herbert, and Joseph. "Sustained release dosage form." VARGHESE publishing house. 400014, 1990; 430-456.

24. Patra S, Chaudhury A. A., Kar R.K., and Barik B. B. Spectrophotometry method for Ondansetron. Ijps journal on Ondansetron, 2007; no.69 (6):840-841. https://doi.org/10.4103/0250-474X.39449

25. Panchal VU, and chauhan PS. "Simultaneous determination of Ondansetron hydrochloride and pantoprazole sodium in their bulk dosage form by ratio derivative spectroscopy". UJPBS, 2013; 1(01):37-41.

26. Kalaichelvi R, MadhvanRao B, Manikanta S, Gopainath G, Usha M, Venkata Raman D, Srinivasa D, Jayachandran E. "Uv spectrophotometric method for determination of ondansetron hydrochloride in pure and its formulation".International journal of pharmacy and pharmaceutical sciences, no.4, 2012; 151-152.

27. SuneethaA, and ChandanaPriya T. "Rp - HPLC method for simultaneous estimation of paracetamol and Ondansetron in bulk and oral suspension". Journal of pharmaceutical research, 2014; (4):106-110. https://doi.org/10.18579/jpcrkc/2014/13/4/78375

28. Yadav S., Padhi S., and Kumar P. "Design and characterization of floating tablet of ondansetron hydrochloride for gastricretation", Pharmacophore, 2014; 5(4):467-476 